\title{
Investigation of the Protective Effect of Nigella Sativa Oil in Cisplatin Induced Oral Mucositis: An Experimental Study
}

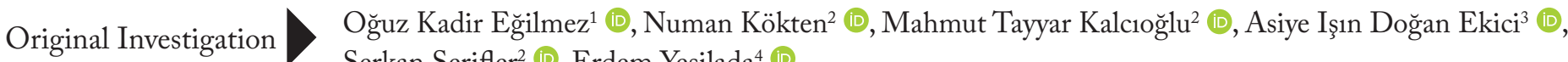 \\ Serkan Şerifler ${ }^{2}$ (D), Erdem Yeşilada ${ }^{4}$ (D) \\ ${ }^{1}$ Department of Otorhinolaryngology, Sakarya University Training and Research Hospital, Sakarya, Turkey \\ ${ }^{2}$ Department of Otorhinolaryngology, İstanbul Medeniyet University Göztepe Training and Research Hospital, İstanbul, Turkey \\ ${ }^{3}$ Department of Pathology, Yeditepe University School of Medicine, İstanbul, Turkey \\ ${ }^{4}$ Department of Pharmacognosy, Yeditepe University School of Pharmacy, İstanbul, Turkey
}

Abstract

ORCID IDs of the authors: O.K.E. 0000-0001-9623-9152; N.K. 0000-0001-6674-9389; M.T.K. 0000-0002-6803-5467; A.I.D.E. 0000-0003-4062-9519; S.S. 0000-0003-0771-7373; E.Y. 0000-0002-1348-6033.

Cite this article as: Eğilmez OK, Kökten N, Kalcıoğlu MT, Doğan Ekici Al, Şerifler S, Yeşilada E. Investigation of the Protective Effect of Nigella Sativa Oil in Cisplatin Induced Oral Mucositis: An Experimental Study. Turk Arch Otorhinolaryngol 2020; 58(1): 10-5.

Corresponding Author:

Mahmut Tayyar Kalcıoğlu, mtkalcioglu@hotmail.com Received Date: 02.09.2019 Accepted Date: 16.12 .2019

Content of this journal is licensed under a Creative Commons Attribution 4.0 International License. Available online at www.turkarchotolaryngol.net
Objective: The aim of this experimental study was to investigate the histopathologic effect of Nigella Sativa oil (NSO) on cisplatin (Cis) induced oral mucositis $(\mathrm{OM})$ in rats.

Methods: Twenty-four rats were divided into four equal groups. The animals in Group 1 and Group 2 were given $5 \mathrm{mg} / \mathrm{kg}$ intraperitoneal (ip) Cis systemically on the $1^{\text {st }}, 3^{\text {rd }}$ and $5^{\text {th }}$ days of the study. Additionally, $15 \mathrm{~mL}$ NSO were given to the rats in Group 2 , with gavage feeding on days $1,3,5,7$, and 9 . The animals in Group 3 were given per oral $15 \mathrm{ml} \mathrm{NSO}$ on days 1, 3, 5, 7 and 9. As the control group, Group 4 received a total of $15 \mathrm{~mL} 0.9 \%$ saline solution divided into 5 doses on days 1, 3, 5, 7 and 9 by oral gavage. On the $14^{\text {th }}$ day, animals were euthanized and buccal mucosa from both sides, including submucosal tissues, were excised and taken to histopathological examination.

Results: The mean mucosal thicknesses of the groups were $224.58 \mu \mathrm{m}, 276.1 \mu \mathrm{m}, 323.33 \mu \mathrm{m}$, and $331.33 \mu \mathrm{m}$, respectively for Groups $1,2,3$, and $4(\mathrm{p}<0.05)$. When the degree of mucosal inflammation was examined, the most intense inflammation was detected in Group 1 and the least intense inflammation was in Group 4 $(p<0.01)$. The degree of inflammation in Group 2 and Group 3 were similar to Group 4 ( $p>0.05$ ).

Conclusion: According to the results of this study, NSO, for which anti-inflammatory and antioxidant properties have been shown in previous studies, may also be effective in preventing Cis-induced OM.

Keywords: Nigella sativa oil, cisplatin, oral mucositis, animal experimentation

\section{Introduction}

More than half a million new head and neck cancers are seen in the world in a year (1). In Europe, 139,000 new head and neck cancer cases are reported each year (2). Chemotherapy is one of the important options in the treatment of head and neck cancers. One of the most commonly used agents is Cis-diamminedichloroplatinum ( $\mathrm{Cis)}$ (3).

Cis is used for the treatment of head and neck cancers as well as genitourinary, lung, esophagus, stomach, colon, testis, ovary, and bladder cancers (4-6). It acts similarly to alkylating agents. It kills malignant cells at all stages of the cell cycle. It binds to DNA, prevents transcription and replication, therefore, DNA synthesis is prevented (7, 8). In addition to its therapeutic effect, many side effects such as myelosuppression, nephrotoxicity, oral mucositis (OM), ototoxicity, peripheral neuropathy, thromboembolism, and tumor lysis syndrome can be seen during Cis treatment (3).

There is no definitive method to prevent or treat OM secondary to chemotherapy. Current treatments show limited efficacy in cancer patients. Nutritional support, palliative care and also phytotherapeutic agents have been shown to be effective in preventing chemotherapy-induced OM in animal studies $(9,10)$.

Nigella sativa (NS) is a plant species belonging to the Ranunculaceae family. NS seeds have been used as spices, and supplements food material in the Middle Eastern and the Mediterranean countries for centuries. NS contains tocopherol, thymo- 
quinone, carvacrol, $\mathrm{t}$-anethol, and 4-terpineol, which neutralize free radicals.

Antimicrobial, anti-inflammatory, antioxidant, antihistaminic, cytoprotective, and antineoplastic effects of NS have been explored in some in-vitro and in-vivo studies with successful results $(11,12)$. To our knowledge, however, there are no studies on the effect of NS on oral mucositis. The aim of this study was to investigate the protective effects of NS on oral mucositis induced by $\mathrm{C}$ is in rats.

\section{Methods}

\section{Ethical Approval}

The study was approved by the Experimental Animals Ethics Committee of Yeditepe University (February 2, 2017-585).

\section{Animals}

Twenty-four healthy adult male Wistar albino rats, weighing 250-300 $\mathrm{g}$ were used. The rats were kept in a temperature-controlled room $\left(21^{\circ} \mathrm{C} \pm 2\right)$, in a dark/light cycle of 12 hours, with free access to food and water, and in cages with a humidity of $55 \% \pm 10$.

\section{Chemicals}

Nigella sativa oil (NSO) (Zade Vital Natural Supplements, Konya, Turkey) was administered by gavage feeding. NSO was produced by cold extrusion and as stated by the manufacturer contained; linoleic acid (57.537\%), palmitic acid (11.75\%), oleic acid (23.851\%), cis-11,14-eicosapentaenoic acid (2.413\%), stearic acid (3.086\%), gondoic acid (0.33\%), arachidic acid (0.194\%), linolenic acid (0.247\%), myristic acid (0.139\%), palmitoleic acid (0.171\%), erucic acid $(0.085 \%)$, behenic acid $(0.030 \%)$, heptadecanoic acid (0.064\%), cis-10 -heptadecanoic acid (0.044\%), lignoceric acid (0.023\%) and cis-13,16-docosahexaenoic acid (0.037\%).

Cis (cis-diamminedichloroplatinum of $0.5 \mathrm{mg} / \mathrm{mL}$, Liba Drug Co., Istanbul, Turkey) was administered intraperitoneally (ip).

Xylazine (Rompun, Bayer) and ketamine hydrochloride (Ketalar, Eczacıbaşı, İstanbul, Turkey) were used for anesthetizing the rats.

\section{Experimental Design}

The animals were randomly divided into four groups of six rats each. Group 1 was administered a total of $15 \mathrm{mg} / \mathrm{kg}$ Cis ip divided into three equal doses on days 1,3 and 5.The rats in Group 2 received $15 \mathrm{~mL}$ NSO by gavage feeding divided into five doses on days $1,3,5,7$ and 9 and $15 \mathrm{mg} / \mathrm{kg}$ Cis was administered ip on days 1,3 and 5 . Group 3 received $15 \mathrm{~mL}$ NSO by gavage feeding divided into five doses on days 1, 3, 5, 7 and 9. In Group 4, 15 $\mathrm{ml}$ of $0.9 \%$ saline solution divided into five doses and were given orally by gavage on days 1, 3, 5, 7 and 9 .

We explored the preventive effect of NSO via using consecutive high doses to obtain optimum systemic effect in a short time. As reported in the literature (13-15), oral usage of $10 \mathrm{~mL} / \mathrm{kg}$, even $2 \mathrm{~g} / \mathrm{kg}$ NSO did not have any serious toxic effect in rats and mice, therefore we used $15 \mathrm{~mL}$ of NSO (approximately equivalent to $10 \mathrm{~mL} / \mathrm{kg}$ ) divided into 5 doses on days $1,3,5,7$ and 9 , which represents a maximum nontoxic dose.

\section{Anesthesia}

Animals were sedated with the ip administration of $7.5 \mathrm{mg} / \mathrm{kg}$ xylazine and $50 \mathrm{mg} / \mathrm{kg}$ of ketamine hydrochloride.

\section{Histopathological Examination}

On the $14^{\text {th }}$ day of the experiment, animals were decapitated by guillotine after carbon dioxide inhalation. The right and left side oral mucosal tissues including the submucosa were excised for histopathological examination in two separate samples. The samples were fixed in $10 \%$ formal saline for 24 hours. They were then dehydrated and cleaned and embedded in paraffin wax. Sections of 5 micrometers $(\mu \mathrm{m})$ thickness were taken and stained with hematoxylin and eosin (H\&E) for light microscopy studies.

Tissues were evaluated by a single pathologist blinded to the study groups using a light microscope (Olympus BX53, Olympus Corporation, Tokyo, Japan) at x200 magnification. Measurements were made quantitatively using an Olympus DP73 camera (Olympus Corporation, Tokyo, Japan) and digital microscopy software, and all parameters were classified separately. The classification was made in accordance with previous studies (16) as follows: 1 = epithelial and connective tissue without vasodilatation, absence or low cellular infiltration, absence of edema, ulceration and abscess; 2 = scattered vasodilatation, areas of reepithelization, diffuse cell infiltration with multiple mononuclear leukocytes, and absence of bleeding, edema, ulcers and abscesses; 3 = moderate vasodilatation, epithelial hydropic degeneration (vacuolization), moderate cell infiltration dominated by polymorph nuclear leukocytes, the presence of hemorrhagic areas, edema and rarely small ulcers but absence of abscesses; 4 $=$ marked vasodilation, cell infiltration with multiple polymorph nuclear leukocytes, presence of hemorrhagic sites, presence of edema and ulceration, and absence of abscess; 5 = severe vasodilatation and inflammatory infiltration, characterized by neutrophils, abscesses and diffuse ulcers. In addition, epithelial thickness in each sample was measured in $\mu \mathrm{m}$ and noted.

\section{Statistical Analysis}

To analyze the differences in microscopic scores between the four groups, the Statistical Package for Social Sciences version 22.0 (IBM Corp., Armonk, NY, USA) program was used. Fisher's exact $\mathrm{x} 2$ and Kruskal-Wallis tests were used to compare the data. Significance level was accepted as $\mathrm{p}<0.05$.

\section{Results}

A rat from Group 2 was excluded from the study because of death after anesthesia on the first day of the experiment.

In histopathological examination, epithelial thickness was found 55 to $350 \mu \mathrm{m}$ (mean, $224.58 \mu \mathrm{m} \pm 103.139)$ in Group 1; 90 to $376 \mu \mathrm{m}$ (mean, $276.1 \mu \mathrm{m} \pm 80.97$ ) in Group 2; 220 to 450 $\mu \mathrm{m}$ (mean, $323.33 \mu \mathrm{m} \pm 77.404$ ) in Group 3; and 200 to $414 \mu \mathrm{m}$ 
(mean, $331.33 \mu \mathrm{m} \pm 62.248$ ) in Group 4 (Figure 1). When Group 1 was compared with the other groups, the difference was significant ( $\mathrm{p}=0.005$ for all groups). The comparisons between the other groups were not significant $(\mathrm{p}=0.356,0.065$ and 0.583 for Group pairs 2-3, 2-4 and 3-4, respectively) (Table 1).

When the degree of mucosal inflammation was evaluated, none of the groups had signs of inflammation at grade 4 or 5 . The most intense inflammation was detected in Group 1. Intense inflammation was not observed in Groups 2, 3 and 4. The degree of inflammation in Group 2 was similar to that of Groups 3 and 4 (Figure 2). There were significant differences between Group 1 and the other groups in terms of degree of inflammation $(\mathrm{p}<0.001)$. The differences between Groups 2, 3 and 4 were not significant (Table 2).

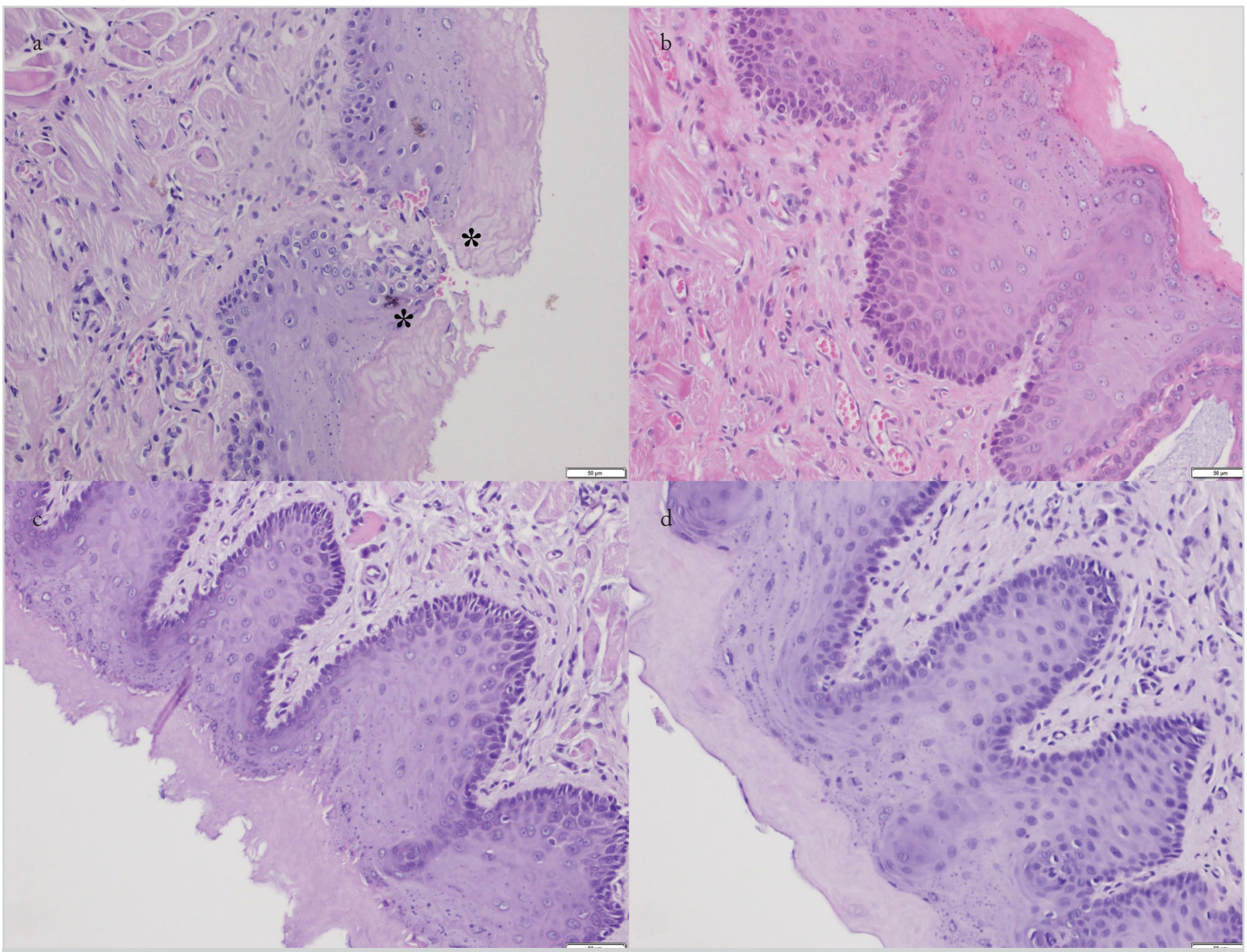

Figure 1. a-d. Histopathological images of epithelial specimens (Hematoxylin \& Eosin staining, x200). (a) Sample from Group 1 (only cisplatin): moderate vasodilatation, epithelial hydropic degeneration (vacuolization), polymorphonuclear leukocytes predominate, moderate cell infiltration, presence of hemorrhagic areas, edema and ulcer areas $\left(^{*}\right)$ are observed. (b) Sample from Group 2 (Cisplatin + Nigella sativa oil): inflammation is partially less, ulcer areas are not observed. (c) Sample from Group 3 (only Nigella sativa), and (d) sample from the control group (Group 4): epithelial and connective tissue without vasodilation is observed, cellular infiltration is much less, edema, ulceration and abscess are not seen

Table 1. Epithelial thickness values of all groups

\begin{tabular}{|c|c|c|c|c|c|c|}
\hline Group & $\mathbf{n}$ & Mean $(\mu \mathrm{m})$ & $\mathrm{SD}$ & Minimum $(\mu \mathrm{m})$ & Maximum $(\mu \mathrm{m})$ & Median $(\mu \mathrm{m})$ \\
\hline Group 1 & 12 & 224.58 & 103.139 & 55 & 350 & 251 \\
\hline Group 2 & 10 & 276.10 & 80.970 & 90 & 376 & 294 \\
\hline Group 3 & 12 & 323.33 & 77.404 & 220 & 450 & 311 \\
\hline Group 4 & 12 & 331.33 & 62.248 & 200 & 414 & 344 \\
\hline
\end{tabular}

p between Group 1 and 2, 3, $4=<0.005$; p between Group 2 and $3=0.356$; p between Group 2 and $4=0.065$; and p between Group 3 and $4=0.583$ n: number of samples; SD: standard deviation 
Table 2. Distribution of inflammation degrees in groups

\begin{tabular}{|c|c|c|c|c|c|}
\hline \multirow[b]{2}{*}{ Group } & \multicolumn{4}{|c|}{ Inflammation Degree } & \multirow[t]{2}{*}{ Total } \\
\hline & 0 & 1 & 2 & 3 & \\
\hline \multirow[t]{2}{*}{ Group 1} & 0 & 5 & 6 & 1 & 12 \\
\hline & $0 \%$ & $41.7 \%$ & $50 \%$ & $8.3 \%$ & $100 \%$ \\
\hline \multirow[t]{2}{*}{ Group 2} & 0 & 8 & 2 & 0 & 10 \\
\hline & $0 \%$ & $80 \%$ & $20 \%$ & $0 \%$ & $100 \%$ \\
\hline \multirow[t]{2}{*}{ Group 3} & 8 & 4 & 0 & 0 & 12 \\
\hline & $66.6 \%$ & $33.3 \%$ & $0 \%$ & $0 \%$ & $100 \%$ \\
\hline \multirow[t]{2}{*}{ Group 4} & 12 & 0 & 0 & 0 & 12 \\
\hline & $100 \%$ & $0 \%$ & $0 \%$ & $0 \%$ & \\
\hline
\end{tabular}

p between Group 1 and other groups $(2,3,4)$ separately $=<0.001$ **p inbetween Group 2, 3, $4=>0.05$

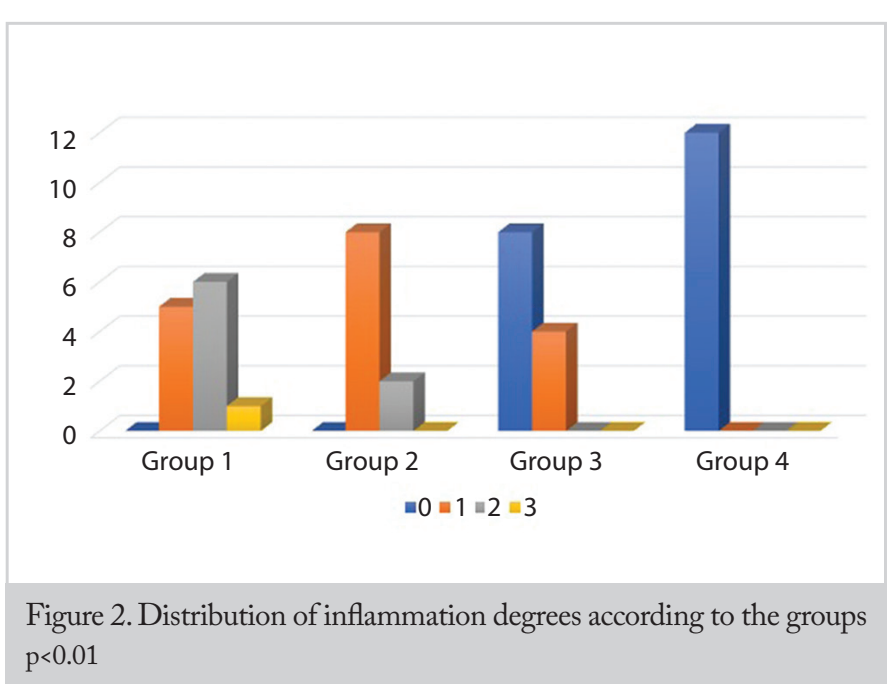

\section{Discussion}

Cis, as part of chemotherapy, has been used in the management of many types of solid tumors for more than 30 years. However, it has reversible or irreversible side effects on many organs including the bone marrow, the gastrointestinal tract, the kidneys, the brain and the inner ear (3-6). One of the side effects is OM. It is an inflammatory condition of the oral and oropharyngeal mucosa caused by cytotoxic effect of the medication. In its most severe form, OM occurs as united, deep ulcers. It may cause pain and affect the quality of life. Severe OM may lead to dose reduction and unplanned discontinuation of cancer therapies. Ulcerative mucositis is also an important risk factor for systemic infection in neutropenic or immunosuppressed patients. This imposes more economic burden and adversely affects the quality of life and survival (9).

The pathophysiology of OM is complex. This happens with several signaling pathways like the nuclear factor kappa $\mathrm{B}(\mathrm{NF \kappa B})$ signal transduction pathway participating in the process. The classical pathway of NFKB is predominantly created by two dimers $\mathrm{p} 50 / \mathrm{p} 65$. They are inactive in the cytoplasm. When they are activated, they migrate to the cell nucleus and then interfere with gene transcription. In OM, NFKB increases the pro-inflammatory cytokines expressions, such as interleukin-1 alpha, tumor necrosis factor alpha, cyclooxygenase-2, transforming growth factor-gamma, and matrix metalloproteinase. Pro-inflammatory cytokines damage the connective tissue. This causes activation on mucosal epithelial signaling. Thereby the lesion is strengthened (17-19).

Current treatments against chemoterapy-induced mucositis have very limited efficacy. Although there is no definitive treatment for the prevention or treatment of OM, nutritional support and palliative care have shown good results (9). Oral hygiene is a key factor in the prevention and the reduction of oral mucosal injury; therefore, educating the patient on oral hygiene is very important to reduce microbial burden. To prevent the side effect, cryotherapy, keratinocyte growth factor-1 (KGF1), low-level laser therapy, benzydamine mouthwash, and zinc are recommended $(9,20)$. In a systematic review on OM treatment in cancer patients receiving chemotherapy, benzydamine mouthwash is recommended for the prevention of OM (21). Another meta-analysis, however, has reported no therapeutic or preventive results of chlorhexidine on OM (22). Additionally, it was reported that substances such as Royal jelly, Lactobacillus brevis lozenges, Palifermin Smecta, Actovegin, Kangfuxin, and phytotherapeutic extracts might have effects on the prevention and the treatment of $\mathrm{OM}(10,23)$.

Control of oxidative stress is important in the prevention and the treatment of OM. Some studies report that antioxidant agents such as edaravone and sesame oil might be effective in solving this problem $(24,25)$. Nakajima et al. (24) reported that edaravone prevented $\mathrm{OM}$ and the effect was due to the antioxidant properties. In spite of all these reports, OM is still seen as one of the important side effects of chemotherapy and impairing the quality of life.

NSO is another plant extract containing tocopherol such as sesame oil. It also contains thymoquinone, 4-terpineol, $\mathrm{t}$-anethol and carvecol which neutralize free radicals $(1,11)$. Traditionally, this herb has been used in the treatment of asthma, hypertension, diabetes, inflammation, cough, bronchitis, headache, fever and gastrointestinal disorders. In clinical and experimental studies, some effects of thymoquinone, which is the main component of NSO, such as anti-inflammatory, 
antibacterial, antihistaminic, antioxidant, cytoprotective, and antineoplastic effects have been reported (11). There are no animal studies in the literature on the effect of NSO in OM. In the current study, the results showed that NSO might have a protective role in preventing oral mucosal damage and be significantly effective in the prevention of $\mathrm{C}$ is-induced superficial erosion of the oral mucosa. According to the results, inflammatory cell infiltration, vascular dilatation, superficial erosion, and exudates were found to be better in rats given Cis plus NSO (Group 2) than those given only Cis (Group 1). The results in Group 2 were also similar to the results of the control groups (Groups 3 and 4). The possible mechanism of action of NSO in preventing oral mucositis caused by cisplatin-induced pro-inflammatory cytokines was anti-inflammatory, antioxidant and cytoprotective effects.

\section{Conclusion}

To the best of our knowledge, this is the first experimental study showing that NSO might be effective in preventing superficial erosion of the oral mucosa caused by $\mathrm{Cis}$. The results of the current study showed that NSO might prevent chemotherapy-induced OM. Further studies are needed to more clearly understand the mechanism of NSO on this subject.

Ethics Committee Approval: Ethics committee approval was received for this study from the Experimental Animals Ethics Committee of Yeditepe University (2.02.2017-585).

\section{Informed Consent: N/A.}

Peer-review: Externally peer-reviewed.

Acknowledgments: We would like to thank to Prof. Hasan Güçlü from the Department of Biostatistics and Medical Informatics of İstanbul Medeniyet University School of Medicine, for his statistical consultation.

Author Contributions: Concept - O.K.E., N.K.; Design - O.K.E., N.K.; Data Collection and/or Processing - A.I.D.E, M.T.K.; Analysis and/or Interpretation - A.I.D.E.; Literature Search - A.I.D.E.; Writing - O.K.E., N.K., S.Ş., A.I.D.E; Critical Reviews - M.T.K., A.I.D.E., E.Y.

Conflict of Interest: The authors have no conflicts of interest to declare.

Financial Disclosure: The authors declared that this study has received no financial support.

\section{References}

1. Çanakci H, Yilmaz AAŞ, Canpolat MS, Şeneldir H, Kir G, Eriş $\mathrm{AH}$, et al. Evaluation of the effect of topical application of nigella sativa on acute radiation-induced nasal mucositis. J Craniofac Surg 2018; 29: e279-82. [Crossref]

2. Grégoire V, Lefebvre JL, Licitra L, Felip E; EHNS-ESMO-ESTRO Guidelines Working Group. Squamous cell carcinoma of the head and neck: EHNS-ESMO-ESTRO Clinical practice guidelines for diagnosis, treatment and follow-up. Ann Oncol 2010; 21 Suppl 5: v184-6. [Crossref]
3. Salem MM, Altayeb ZM. Light and electron microscopic study on the possible protective effect of nigella sativa oil on cisplatin hepatotoxicity in albino rats. EJH 2017; 40: 68-79. [Crossref]

4. Astolfi L, Simoni E, Valente F, Ghiselli S, Hatzopoulos S, Chicca M, et al. Coenzyme Q10 plus multivitamin treatment prevents cisplatin ototoxicity in rats. PLoS One 2016; 11: e0162106. [Crossref]

5. Naples JG, Parham K. Cisplatin-induced ototoxicity and the effects of intratympanic diltiazem in a mouse model. Otolaryngol Head Neck Surg 2016; 154: 144-9. [Crossref]

6. Teranishi MA, Nakashima T. Effects of trolox, locally applied on round windows, on cisplatin-induced ototoxicity in guinea pigs. Int J Pediatr Otorhinolaryngol 2003; 67: 133-9. [Crossref]

7. Ekborn A, Laurell G, Ehrsson H, Miller J. Intracochlear administration of thiourea protects against cisplatin-induced outer hair cell loss in the guinea pig. Hear Res 2003; 181: 109-15. [Crossref]

8. Fetoni AR, Sergi B, Ferraresi A, Paludetti G, Troiani D. Protective effects of alpha-tocopherol and tiopronin against cisplatin-induced ototoxicity. Acta Otolaryngol 2004; 124: 421-6. [Crossref]

9. Al-Ansari S, Zecha JA, Barasch A, de Lange J, Rozema FR, Raber-Durlacher JE. Oral mucositis induced by anticancer therapies. Curr Oral Health Rep 2015; 2: 202-11. [Crossref]

10. Davarmanesh M, Miri R, Haghnegahdar S, Tadbir AA, Tanideh $\mathrm{N}$, Saghiri MA, et al. Protective effect of bilberry extract as a pretreatment on induced oral mucositis in hamsters. Oral Surg Oral Med Oral Pathol Oral Radiol 2013; 116: 702-8. [Crossref]

11. Kokten N, Egilmez OK, Dogan Ekici AI, Kalcioglu MT, Tekin M, Yesilada E. The effect of nigella sativa oil on prevention of myringosclerosis in a guinea pig model. Int J Pediatr Otorhinolaryngol 2016; 88: 52-7. [Crossref]

12. Kocoglu E, Kalcioglu MT, Uzun L, Zengin F, Celik S, Serifler S, et al. In vitro investigation of the antibacterial activity of nigella sativa oil on some of the most commonly isolated bacteria in otitis media and externa. Eurasian J Med 2019; 51: 247-51. [Crossref]

13. el Daly ES. Protective effect of cysteine and vitamin E, crocus sativus and nigella sativa extracts on cisplatin-induced toxicity in rats. J Pharm Belg 1998; 53: 87-93.

14. Khanna T, Zaidi FA, Dandiya PC. CNS and analgesic studies on nigella sativa. Fitoterapia 1993; 64: 407-10.

15. Zaoui A, Cherrah Y, Mahassini N, Alaoui K, Amarouch H, Hassar M. Acute and chronic toxicity of nigella sativa fixed oil. Phytomedicine 2002; 9: 69-74. [Crossref]

16. Watanabe S, Suemaru K, Nakanishi M, Nakajima N, Tanaka M, Tanaka A, et al. Assessment of the hamster cheek pouch as a model for radiation-induced oral mucositis, and evaluation of the protective effects of keratinocyte growth factor using this model. Int J Radiat Biol 2014; 90: 884-91. [Crossref]

17. Ribeiro SB, de Araújo AA, Araújo Júnior RF, de Castro Brito GA, Leitão RC, Barbosa MM, et al. Protective effect of dexamethasone on 5-FU-induced oral mucositis in hamsters. PLoS One 2017; 12: e0186511. [Crossref]

18. Logan RM, Gibson RJ, Sonis ST, Keefe DM. Nuclear factor-kap$\mathrm{paB}(\mathrm{NF}-\mathrm{kappaB})$ and cyclooxygenase-2 (COX-2) expression in the oral mucosa following cancer chemotherapy. Oral Oncol 2007; 43: 395-401. [Crossref]

19. Park MH, Hong JT. Roles of NF-кB in cancer and inflammatory diseases and their therapeutic approaches. Cells 2016; 5: 15. [Crossref]

20. Sung L, Robinson P, Treister N, Baggott T, Gibson P, Tissing W, et al. Guideline for the prevention of oral and oropharyngeal mucositis in children receiving treatment for cancer or undergoing haematopoietic stem cell transplantation. BMJ Support Palliat Care 2017; 7: 7-16. [Crossref] 
21. Ariyawardana A, Cheng KKF, Kandwal A, Tilly V, Al-Azri AR, Galiti D, et al. Systematic review of anti-inflammatory agents for the management of oral mucositis in cancer patients and clinical practice guidelines. Support Care Cancer 2019; 27: 3985-95. [Crossref]

22. Cardona A, Balouch A, Abdul MM, Sedghizadeh PP, Enciso R. Efficacy of chlorhexidine for the prevention and treatment of oral mucositis in cancer patients: A systematic review with meta-analyses. J Oral Pathol Med 2017; 46: 680-8. [Crossref]
23. Daugèlaitė G, Užkuraitytė K, Jagelavičienė E, Filipauskas A. Prevention and treatment of chemotherapy and radiotherapy induced oral mucositis. Medicina (Kaunas) 2019; 55: 25. [Crossref]

24. Nakajima N, Watanabe S, Kiyoi T, Tanaka A, Suemaru K, Araki $\mathrm{H}$. Evaluation of edaravone against radiation-induced oral mucositis in mice. J Pharmacol Sci 2015; 127: 339-43. [Crossref]

25. Johnsen J, Bratt BM, Michel-Barron O, Glennow C, Petruson B. Pure sesame oil vs isotonic sodium chloride solution as treatment for dry nasal mucosa. Arch Otolaryngol Head Neck Surg 2001; 127: 1353-6. [Crossref] 